\title{
A construção de um dispositivo que permita estudar os discursos que organizam o campo da saúde: um ensaio sobre os efeitos discursivos e a formação do profissional em saúde
}

| ${ }^{1}$ Roberto H. Amorim de Medeiros |

Resumo: Partindo das ideias centrais do artigo "O quadrilátero da formação para a área da saúde: ensino, gestão, atenção e controle social", de Ceccim e Feuerwerker, publicado no ano de 2004 no volume 14 desta revista, o autor procura trazer contribuiçôes à questão ao propor um ensaio teórico no qual cada elemento do quadrilátero será pensado como estruturante de discursos específicos. Para tanto, faz intervir a teoria dos quatro discursos de Jacques Lacan para proceder à construção de cada discurso e realizar as primeiras análises de seus efeitos no campo da formação do profissional em saúde. Após uma introdução elementar sobre aquela teoria, o autor passa a articular reflexivamente os elementos do quadrilátero entre si e a construir com o leitor cada um dos discursos, a saber, do Ensino, da Gestão, da Atenção e do Controle Social. Este último é trabalhado com mais detalhe, segundo os próprios argumentos do artigo de origem que lhe dá destaque, e passa a ser renomeado como Discurso do Usuário, para enfatizar o elemento subjetivo suposto neste discurso. Ao final, são apresentados alguns encaminhamentos para futuras pesquisas a partir de uma série de interrogações que a construção e as primeiras observações sobre os efeitos dos discursos estudados suscitaram. Este trabalho procura colaborar na mesma linha da pesquisa do artigo que o originou e levantar questôes que permitam elucidar as condições de possibilidade do ingresso do sujeito como elemento do jogo estrutural que interfere e produz os atos no campo da saúde, assim como a formação do profissional nesse contexto.

> Palavras-chave: formação em saúde; controle social; quatro discursos; Lacan; educação dos profissionais de saúde.
1 Psicólogo do Serviço de Saúde Comunitária do Grupo Hospitalar Conceição (GHC) de Porto Alegre-RS, preceptor da Residência Integrada em Saúde da mesma instituição na ênfase de Saúde da Família e Comunidade e doutorando em Educação pela FACED Faculdade de Educação da Universidade Federal do Rio Grande do Sul - UFRGS, onde pesquisa sobre a formação do profissional em saúde. Endereço eletrônico: robertoamorim80@ hotmail.com

Recebido em: 08/12/2008. Aprovado em: 30/11/2009. 
No artigo "O quadrilátero da formação para a área da saúde: ensino, gestão, atenção e controle social", Ceccim e Feuerwerker (2004) propõem que a formação do profissional em saúde se encontre sustentada através das articulações entre Ensino, Gestão, Atenção e Controle Social, com privilégio deste último como organizador das políticas e dos serviços nessa área. O texto argumenta que, embora o advento do SUS tenha provocado discussões importantes acerca da formação em saúde, ainda faltam mais debates para que se formulem modos de estruturá-la objetivamente. Uma das propostas centrais do texto parece indicar um caminho: a busca do incremento da articulação entre as várias instâncias de gestão do sistema de saúde com as instituições formadoras, cujo papel é hegemônico nesse campo. Acrescenta, no mesmo rumo, que a educação em serviço, proporcionada aos técnicos e demais profissionais da saúde, deve ter o status de política pública e organizar-se conforme os pressupostos da Educação Permanente assumida como lógica de produção de sentidos e crítica dos processos criativos de trabalho. A ética da clínica ampliada ${ }^{1}$ seria um dos norteadores necessários às ações em saúde dos vários serviços do SUS, constituindo-se na condição essencial para a efetivação da diretriz de integralidade na atenção à saúde da população. Finalmente, a exemplo do que assevera Cecílio (1997), os autores sustentam a necessidade da extensão das características do nível primário de cuidados em saúde - acolhimento, vínculo, responsabilização, desenvolvimento da autonomia dos sujeitos e resolutividade aos demais serviços componentes da rede.

A representação quadrilátera da formação em saúde, segundo propõem os autores, supõe necessariamente articulações entre seus quatro elementos. Assim, Ensino (E), Gestão (G), Atenção (A) e Controle Social (CS) constituem núcleos de forças que se relacionam, resistem, conjugam, anulam-se ou amplificam-se, ao organizarem uma determinada estrutura.

A seguinte representação do quadrilátero tenta ilustrar as possíveis relações entre seus quatro pontos de sustentação.

Figura 1

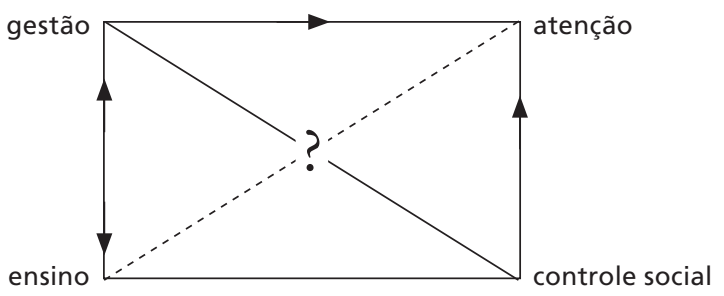


Essa é uma primeira configuração que merece algumas observaçōes. $G$ aparece em relação recíproca e direta com E, e, depois, em relação unidirecional com A. A primeira situação justificar-se-ia pela dependência da sustentabilidade das ações gerenciais promovida pela produção de conhecimentos - a ciência administrativa - e pelo efeito de rebote que a gestão pode exercer nas diretrizes de ensino. A segunda situação parece clara, na medida em que a gestão interfere diretamente nos processos de trabalho, mas nem sempre há participação do trabalhador no processo gerencial.

A principal observação a ser feita, entretanto, diz respeito à posição do CS, visto que ele tem papel central na argumentação do artigo citado. No esquema, o CS aparece tendo influência no elemento A, o que ilustra a relação direta do usuário com os dispositivos e profissionais de saúde - através de conferências, conselhos e assembleias e no cotidiano das relações. $\mathrm{O}$ eixo transversal descontínuo e não orientado EA, configura-se na relação direta do ensino - da ciência - com as técnicas e saberes produzidos na atenção à saúde. E e A estão em constante relação e constituem um eixo imaginário. O que se ensina na Universidade é a imagem ideal a ser refletida no registro prático do trabalho; aquilo que responde pela boa técnica e sustenta o discurso da qualidade dos serviços em saúde. Finalmente, as articulações entre CS e E são apenas indicadas como possibilidades que precisam ser mais bem estudadas, segundo a própria proposta do trabalho de Ceccim e Feuerwerker.

$\mathrm{Na}$ conclusão do referido artigo, encontramos a seguinte passagem: “[...] no quadrilátero estão aspectos éticos, estéticos, tecnológicos e organizacionais, operando em correspondência, agenciando atos permanentemente reavaliados e contextualizados." (CECCIM; FEUERWERKER, 2004, p. 59; grifos meus). Essa colocação, se articulada ao que está representado na figura 1, parece permitir que tomemos cada elemento do quadrilátero como produtor de determinados discursos. A arqueologia de Foucault nos ensina que os jogos de saber/poder são produtos e produtores de discursos. Estes, por sua vez, têm o potencial de gerar políticas com seus dispositivos e consequentes tecnologias. Parece possível, portanto, realizar uma leitura da mesma articulação proposta, tomando, por exemplo, o Ensino como elemento por excelência constituído pelo discurso da ciência; a Gestão pelo discurso político (RH, tecnologias); a Atenção sustentada pelo discurso técnico dos profissionais da saúde; e o Controle Social agindo através do discurso da população usuária. Se não, vejamos: a extensa nota de 
rodapé de número seis do artigo em questão (CECCIM; FEUERWERKER, 2004, p. 63-64), na qual os autores discorrem sobre o conceito de integralidade em saúde, possibilita fazer recortes (grifados, abaixo), a título de ilustração, que podem ser lidos como efeitos de cada tipo de discurso. Citamos alguns deles:

a) "[...] implica que todo o sistema de saúde seja capaz de acolher e responsabilizarse pelas necessidades dos usuários e não apenas diagnosticar e tratar segundo os padróes técnicos definidos pelos profissionais e pelos serviços [...]" (efeito do discurso da ciência).

b) "[...] a cadeia de cuidado progressivo à saúde propõe à garantia do acesso a todas as tecnologias disponíveis para enfrentar as doenças e prolongar a vida, [...]" (efeito do discurso do controle social).

c) "[...] o que se observa em geral nas propostas de hierarquia de complexidade crescente [...]" (efeito do discurso da gestão).

Nessa nota, porém, não aparece o que poderia ilustrar o efeito do discurso do técnico, aquele que presta a atenção à saúde. ${ }^{2}$ Podemos avançar perguntando: como se articulam os discursos? Como suas linhas de tensão entrecruzam-se, tramam e produzem os dispositivos e as tecnologias na área da saúde? Quais seriam os efeitos possíveis do discurso do CS nesse contexto?

Os discursos são modalidades de tratamento do outro, que deve ser entendido como outro do laço social que o discurso institui - ao invés do outro enquanto $o$ semelhante, nosso outro imaginário - e que ocupa determinadas posições quando submetido às relações discursivas em tensão. Embora tenhamos feito, há pouco, uma tentativa de ilustração dos possíveis efeitos de discursos encontrados no próprio texto do artigo, é importante deixar claro que o conceito de discurso do qual fazemos uso prescinde de palavras. O discurso é o que produz os atos e as formas de gozo em que se envolvem seus participantes por estarem inseridos na sua lógica. $\mathrm{O}$ conceito de discurso a que nos referimos não se constitui de palavras, mas é, finalmente, o que faz agir, pensar e falar, no contexto do laço social que ele mesmo institui.

O psicanalista francês Jacques Lacan (1901-1981), inspirado pelos acontecimentos de maio de 1968, na França, procurou direcionar sua pesquisa psicanalítica ao estudo dos laços sociais e da posição do discurso analítico naquele contexto. No seminário intitulado $O$ avesso da psicanálise, proferido entre os anos de 1969 e 1970, Lacan (1992) procurou formalizar, através da dialética hegeliana, do marxismo, da matemática e da lógica moderna, um estudo sobre as 
possibilidades de subversão aos discursos vigentes, o que viria a chamar de discurso analítico. Ao mesmo tempo, Lacan problematizava a ética da psicanálise e dava ao ensino de Freud um contexto científico ao construir verdadeiras ferramentas de pesquisa psicanalítica.

Para auxiliar nossa pesquisa acerca dos discursos, suscitada pelo artigo em foco, propomos que nos inspiremos no dispositivo criado por Lacan, para que se estabeleça a viabilidade de postularmos a existência de determinados discursos, segundo sua definição, no contexto da área da saúde e observar a que conclusões podemos chegar através do seu uso. Para operar com os discursos e pesquisar como se relaciona o discurso analítico, foco de sua pesquisa, Lacan constrói formalmente um sistema em que se articulam quatro discursos: do mestre, da universidade, do analista e da histeria. Nesse dispositivo de pesquisa, existem quatro lugares e quatro termos que os ocupam sucessivamente, dando origem a cada discurso.

\author{
Os termos são: \\ S1: o significante (sê-lo) mestre \\ S2: o saber \\ \$: o sujeito \\ a: o objeto mais-gozar
}

Os lugares possíveis de serem ocupados pelos termos no dispositivo são:

$\frac{\text { o agente }}{\text { a verdade }} \quad \frac{\text { o outro }}{\text { a produção }}$

O uso do dispositivo é simples, na medida em que se trata de verificar o efeito significante que o posicionamento de cada um dos termos acaba por produzir como discursos que organizam laços no registro social. Portanto, o movimento gradual dos termos de $1 / 4$ de volta no sentido horário irá produzir cada um dos quatro discursos.

As conclusões lacanianas acerca do papel do discurso analítico como subversão aos demais discursos e as decorrências da utilização desse dispositivo para a clínica e a pesquisa psicanalítica não serão o foco deste artigo. No entanto, para fazermos nossa utilização do instrumento, seguem algumas considerações sobre o modelo lacaniano.

Cada um dos quatro discursos organiza um determinado laço social que se estrutura a partir da relação do agente do discurso com o seu outro, o que faz 
com que este último produza algo a partir de um lugar autorizado pelo discurso, o lugar de verdade. Em todo discurso, os quatro termos estão presentes e sua posição determina o que é específico em cada um. Assim, à medida que cada termo vá ocupando o lugar do agente - através do giro horário de 1/4 de volta -, emergem diferentes discursos.

No discurso do mestre, representado abaixo, o governante (agente) obtém do governado (o outro) a produção de objetos (mais-gozar) de gozo.

$$
\frac{\mathrm{S} 1}{\$} \quad \frac{\mathrm{S} 2}{\boldsymbol{a}}
$$

Um giro de 1/4 de volta coloca o sujeito desejante (a barra representa sua divisão e assim sua incompletude que faz desejar) no lugar do agente, que, por sua vez, se autoriza de seu gozo (a no lugar da verdade), provocando que o mestre (S1 no lugar do outro) produza um saber (S2 no lugar da produção).

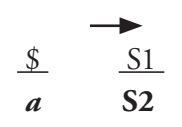

Perceba-se, por fim, que cada discurso ordena um ato no laço social. Nos exemplos acima, podemos admitir, no primeiro caso, o modelo de um ato governamental produzido pelo discurso do mestre (em ato). ${ }^{3}$ No segundo caso, o surgimento do que veio a chamar-se de Psicanálise, a partir dos estudos sobre a histeria de Freud e Breuer, é exemplo do efeito do ato histérico como denúncia do desejo irreconhecido das mulheres na era vitoriana. Nessa lógica, podemos seguir afirmando que o ato de educar, promovido pelo discurso da Universidade (S2 no lugar do agente) é o tratamento do outro objetivado pelo saber. No contexto da sala de aula ${ }^{4}$ é o que autoriza o educador, a partir do saber do autor científico (artigos em periódicos, por exemplo), a impor este saber ao aluno.

Tentemos agora utilizar a lógica da teoria dos quatro discursos para estudar como seriam as relações entre os elementos que organizam a formação de profissionais em saúde, a partir da ideia do quadrilátero.

Redefinindo os termos a partir do discurso do mestre e pela via das relações entre os elementos propostas na figura 1, sugerimos derivar outro tipo de configuração, usando a lógica lacaniana. $\mathrm{O}$ discurso da gestão, do mestre como 
governante, parece poder ser escrito da seguinte forma:

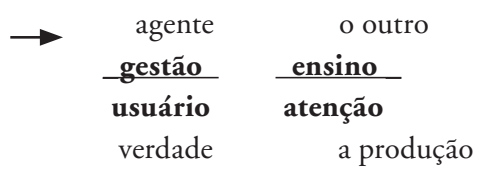

A configuração obtida mostra que o posicionamento da gestão como agente da formação faz o ensino (graduações, residências, cursos técnicos) produzir os processos de trabalho (a atenção) em saúde. A gestão agencia esse ato, dizendo-se sustentada pelas demandas e necessidades do usuário para produzir os serviços de atenção à saúde. Contudo, a parte de baixo do esquema dos quatro discursos sempre marca uma impotência e nesse caso está indicando que a atenção à saúde, quando produzida apenas sob o domínio do discurso da gestão dos serviços e dos profissionais, frequentemente, fica aquém da verdade do usuário. $\mathrm{Na}$ parte de cima, a relação de poder da gestão com o ensino parece produzir a normatização da atenção à saúde: controle e estabelecimento de fluxos, teorizações sobre as portas de entrada no SUS etc. Cabe salientar que a parte de cima do esquema marca sempre uma impossibilidade.

Fazendo o giro de $1 / 4$ de volta dos elementos no modelo, o que representa uma mudança de discurso, encontramos o seguinte:

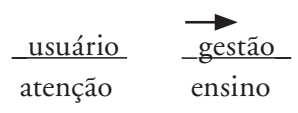

Nesse discurso, o usuário é o agenciador. O trabalho da gestão dos serviços organizados por esse discurso seria o meio pelo qual deve se produzir algum ensino do profissional em saúde. No lugar de agente, o usuário estabelece a situação em que o ensino não se dá desvinculado da sua verdade, aqui representada pela prática da atenção em saúde. Essa seria a lógica, por exemplo, da formação proposta pelas Residências, que se estruturam no cotidiano dos serviços em saúde. Perceba-se, ainda, que é nesse discurso que a atenção ocupa o lugar de verdade sustentando a demanda do usuário. Nessa posição, o modelo está representando o que se pode chamar também de Controle Social, de acordo com o que propõe o artigo do quadrilátero (CECCIM; FEUERWERKER, 2004). É curioso perceber que o ensino (a educação) encontra-se no lugar daquilo que é produzido por um discurso 
quando o usuário ocupa o lugar do agente. É por intermédio do trabalho da gestão que algum conhecimento sobre a saúde do usuário pode ser produzido, sustentado pela atenção no lugar de verdade. Parece que a noção básica do que se convencionou chamar de Educação Permanente (CECCIM, 2005), no contexto da prática do cuidado em saúde para a formação do profissional, é uma possível representação de efeitos desse discurso.

Com um novo movimento no modelo, muda-se para um discurso no qual a dominante passa a ser a atenção em saúde:

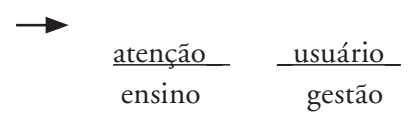

Percebe-se que o discurso da atenção, que organiza o fazer e o saber técnico, é sustentado pelo ensino que ocupa o lugar da verdade. Nesse discurso, parece ser o papel do técnico, do profissional em saúde, colocar-se como causador do desejo que permita ao usuário (o paciente) produzir a (auto)gestão de seu processo de cura. É interessante perceber que a montagem do discurso da atenção mostra o que se espera como resultado do agenciamento do profissional no contexto dos serviços em saúde: costuma-se assumir, entre os pressupostos básicos do que se entende por integralidade dos atos em saúde, a autonomia e a corresponsabilização do usuário como elementos importantes do processo terapêutico. Entretanto, cabe questionarmos nesse discurso, como um profissional ou uma equipe pode perder essa potencialidade no trabalho com o usuário que, com frequência, acaba ocupando um lugar objetal no processo de cura. Ou, talvez, quando isso ocorre, na verdade estaríamos presenciando a forma pela qual a integralidade da atenção pode se transfigurar, quando produzida no contexto de outro discurso? Qual discurso seria esse que coloca o usuário na posição de objeto do ato terapêutico? E, ainda, se concordarmos que esse fato é frequente, em que momentos realmente um profissional ou uma equipe de saúde atua sob o discurso que deveria lhe ser inerente, ou seja, o discurso da atenção?

Com mais um movimento que muda de discurso, damos uma volta completa no dispositivo e chegamos à seguinte configuração:

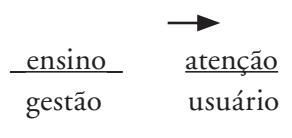


Esse é o discurso do Ensino, que se parece muito, em termos gerais, com o próprio discurso da Universidade, proposto por Lacan (1992). A parte superior do discurso mostra claramente a relação imaginária - assinalada anteriormente na articulação do quadrilátero (figura 1) - do ensino com a atenção. A relação da universidade com o bacharel é um exemplo. O discurso da universidade, como propunha Lacan, organiza um tipo de laço social que produz o ritual da formatura, no qual a instituição garante - e a sociedade aceita - que após a solenidade, o recém-ex-aluno esteja pronto como profissional e já pode ser demandado como o detentor de um saber específico e completo.

O que se produz na Universidade ou nos cursos de pós-graduação, sustentados pela verdade da gestão, é a mais pura burocracia, ao invés do saber. Repetemse os mesmos dogmas indiscutíveis da ciência e o próprio ato de se produzir um questionamento, fundamental à pesquisa, ocupa cada vez menos espaço do período letivo. Um tipo de sujeito é produzido como efeito desse discurso no campo da saúde: aquele que demanda cuidados em conformidade com determinada verdade da gestão e que deseja a cura conforme a produção discursiva da ciência. O exemplo efetivo disso é corriqueiro. Manifesta-se no usuário, no cidadão, no paciente, enfim, que exige o pronto-atendimento no momento em que adoece, como lhe promete a lógica de gestão neoliberal, e uma pílula que lhe trará a felicidade, como lhe promete a ciência.

Antes de encaminhar algumas reflexões sobre o que fora proposto até aqui, cabe chamar a atenção para um último detalhe. Observando que no discurso do ensino o usuário ocupa o lugar do que é produzido, a questão lançada há pouco no contexto do discurso da atenção não teria aí um encaminhamento de resposta? Se uma determinada instituição de saúde funcionar apenas sob a dominância do discurso do ensino, pode correr o risco de tomar o usuário de seus serviços como o objeto pelo qual seus aprendizes acedem ao gozo do conhecimento? Nesse discurso como poderia o usuário ocupar um lugar autônomo e co-responsável nos processos de prevenção, promoção ou reabilitação de sua saúde?

\section{Sugestão de encaminhamentos para pesquisas futuras e novas contribuições}

Este ensaio propõe uma lógica com a qual se possa colocar em análise e refletir acerca dos determinantes do campo da saúde em uma dada situação institucional 
ou momento sócio-histórico. Esse é o principal objetivo ao propor que os elementos do quadrilátero da formação em saúde, segundo Ceccim e Feuerwerker (2004), sejam pensados, não apenas como elementos, mas como os quatro discursos que organizam e produzem os atos e os gozos no campo da saúde. Os demais objetivos poderão ser cumpridos na medida em que o trabalho com o dispositivo dos quatro discursos da área da saúde possa avançar ao ser utilizado como ferramental analisador ou como recurso lógico para as reflexôes teóricas para o entendimento sobre determinadas situações e movimentos do campo em questão.

No momento inicial da proposta, cabe apenas encaminhar algumas questôes que possam inspirar pesquisas futuras, bem como tecer consideraçóes sobre alguns aspectos já tangenciados neste ensaio, em especial sobre o recorte que se refere à formação do profissional em saúde, tendo em vista o foco do trabalho que o originou.

A última pergunta, formulada há pouco na apresentação do discurso do ensino, lançou um problema delicado. Embora o ensino para a formação em saúde seja admitido como um elemento importante para o incremento do trabalho das equipes na atenção - vide o status que obtém um hospital-escola ou uma instituição que comporta programas de Residência Médica ou Integrada com as demais profissões da área da saúde -, a configuração do discurso do ensino traz o problema do gozo do conhecimento sobre o paciente. Ou seja, numa instituição cujo gerenciamento sustenta o discurso do ensino, corre-se o risco de sempre promover uma atenção que, ao reproduzir o discurso científico, pouco esteja atenta às necessidades singulares dos pacientes. Estes acabam por ocupar o lugar de objetos do conhecimento nessa relação. A observação do gozo do conhecimento patrocinado pelo discurso do ensino em uma instituição de saúde não chega a ser novidade, mas corrobora o que a configuração do discurso mostra e questiona sobre seu alcance e pertinência no funcionamento de uma instituição que deve, primordialmente, cuidar da saúde daqueles que dependem dela para isso.

Uma observação importante, levando em conta a problemática que se apresenta no contexto do discurso universitário, ou do ensino, no âmbito das instituições que cuidam da saúde, se dá ao analisarmos se a saída para não incorrer nos excessos dos efeitos de um determinado discurso não seria a possibilidade da circulação entre os quatro discursos, a saber, do ensino, da gestão, da atenção e do 
usuário, na estrutura institucional? Lacan (1985), no seu campo de teorização, afirma que o amor é o signo de que houve troca de discurso. Experimentando ver as consequências de substituir, conforme é permitido pela teoria psicanalítica freudiana, o termo amor pelo termo psicanalítico transferência (FREUD, 1969), perguntamo-nos: uma transferência de que tipo e endereçada ao quê, no contexto do grande campo da saúde, poderia trazer as condições de uma mudança do discurso de mestria da gestão para o do usuário?

Uma instituição atravessada somente por um ou dois discursos dominantes tenderia a ser pouco flexível ao dar tratamento sempre igual as suas questões e problemas. Isto costuma ser o motivo da existência daquela situação, quase sempre justificada e nem sempre estranha quando tomamos conhecimento dela ou a sentimos na própria pele - em que um profissional em saúde se vê obrigado a atender o paciente em cerca de dez minutos, passar a maior parte do exíguo tempo preenchendo formulários e sequer olhar para a face do seu paciente ao encaminhálo ao próximo profissional. Aí está um exemplo de ato patrocinado pelo discurso da gestão - que organiza os tempos, processos de trabalho e de informação, bem como os fluxos - no lugar do que deveria ser mais bem organizado pelo discurso da atenção em saúde.

Assim como nesse específico exemplo, também deve ser possível fazer o exercício de tentar descobrir qual dos discursos é dominante nas mais diversas situações que podemos imaginar ou ter vivenciado, quando em contato com os serviços e ações de uma instituição de saúde. ${ }^{5}$ Desse modo o leitor poderá, além de se familiarizar com o funcionamento do esquema dos quatro discursos do campo da saúde, comprovar que as formas de tratamento do outro pelos discursos da gestão, da atenção e do ensino, são as mais corriqueiras e fáceis de identificar do que as do quarto discurso da estrutura. Também poderá observar as produções peculiares, por vezes equivocadas e distorcidas, quando um determinado discurso ganha prevalência ao dominar as ações que se mostrariam mais adequadas se instituídas pelo discurso natural à situação. Isso ocorre quando um profissional nem se dá conta que o problema de sua prática está em proceder burocraticamente numa consulta em que deveria cuidar da saúde de um paciente, como ilustrado pelo exemplo proposto há pouco.

Sabemos, pela geometria e pela mecânica, que apenas três pontos são suficientes para sustentar satisfatoriamente uma estrutura. Não é de estranhar, 
portanto, que o campo da saúde se estruture essencialmente com a articulação de apenas três elementos, a saber, a gestão, o ensino e a atenção. Os três pontos de apoio formam uma estrutura estável por serem impessoais - não se fala aqui de gestores, professores e profissionais. Assim, estabelecem o jogo de relações no contexto da saúde. A natureza do quarto elemento, entretanto, parece impedir que também o consideremos impessoalmente na denominação Controle Social, pois carrega consigo a emergência de um sujeito como cidadão - o que obriga que o entendamos como participante singular do ato em saúde que a ele se refere. Portanto, não pode ser considerado apenas como coletivo organizado e interveniente na gestão das questões de saúde de uma comunidade, mas como voz ativa e participativa em todos os âmbitos onde se dê um ato em saúde, como por exemplo, até mesmo dentro de um consultório, defrontado com o profissional que lhe atende. É nesse sentido que preferimos chamar a dominante do quarto discurso de usuário, ao invés de controle social, por se referir aos efeitos de cidadania. Esses não implicam apenas na organização política e coletiva de um grupo social, mas podem ser exercidos por todo cidadão que se sentir investido do direito de ocupar seu devido papel responsável pelo espaço público.

A lógica dos quatro discursos prescinde dos sujeitos de carne e osso. Não se trata de discursos na forma de palavras, mas, sim, produção de enunciados, de atos, no campo dado. Porém, o desafio que podemos nos colocar frente a esse fato, seria: como incluir e contar com os efeitos daquele que excede à estrutura, ou seja, o sujeito? ${ }^{6} \mathrm{Na}$ linha que parece cara aos autores do artigo sobre o quadrilátero da formação em saúde (CECCIM; FEUERWERKER, 2004), esse desafio pode ser situado na tentativa de elucidar as condiçôes de possibilidade do ingresso do sujeito como elemento do jogo estrutural que interfere e produz a formação do profissional de saúde, transformando-a, finalmente, em uma estrutura quádrupla.

Uma proposição central do texto do quadrilátero é a que afirma o Controle Social como poder disciplinador da formação e desenvolvimento dos profissionais da saúde. A montagem do discurso do usuário, como o chamamos no presente ensaio, implica que, por intermédio da gestão, seja produzido o ensino. A formação a partir da referência no usuário cria o lugar de verdade para a atenção à saúde. 


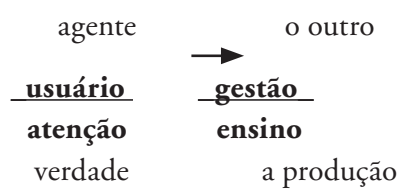

No lado esquerdo do que estamos provisoriamente chamando de discurso do usuário, encontramos a seguinte estrutura: usuário/atenção. A posição da atenção à saúde no lugar de verdade é o que dá sustentação ao usuário como dominante nesse discurso. Essa configuração está a indicar que apenas quando a atenção se estabelece como a verdade do usuário, o referido discurso pode vir a se estruturar e provocar seus efeitos na produção de um ensino a partir do trabalho da gestão. Porém, há que se perguntar: quando a atenção em saúde pode representar uma genuína condição de verdade do usuário para que haja a possibilidade desse discurso surgir? Em quais situações a atenção à saúde atua orquestrada pelo desejo do usuário, ao invés de colocar em primeiro plano o saber de sua ciência, o costume rotineiro de sua técnica ou as exigências gerenciais que moldam seu processo de trabalho? Cabe perguntar em quantos e em quais momentos já pudemos presenciar efeitos do discurso do usuário nas práticas em saúde que tem se levado a cabo em nosso contexto? Onde encontrar essa configuração hipotética? Procurar a resposta é tarefa de seguimento dessa pesquisa. Parece ser um caminho interessante, para iniciar essa busca, os trabalhos que proliferam em nosso contexto sobre a escuta (HECKERT, 2007; RINALDI, 2000), a intersubjetividade (AYRES, 2000; AYRES, 2001) e a valorização do saber do próprio paciente sobre seu padecimento, para colocar em questão, tanto esses trabalhos, como a condição de existência de um discurso do usuário.

O mesmo vale se nos perguntarmos onde está presente o discurso do usuário quando se observa que o ensino e as práticas em saúde nem sempre são satisfatórias ou adequadas para abordar os problemas singulares de diferentes territórios do país ou de uma mesma cidade. Reportando-nos à figura 1 e igualmente inspirados na pesquisa lacaniana, observamos, em linha descontínua, o que poderia chamar-se de muro imaginário da Ciência. Ele é composto pela relação já comentada entre a Universidade e seu produto - o profissional - garantidos e ordenados pelo 
discurso vigente da Ciência em nosso laço social contemporâneo. É o muro que se interpõe entre a relação do usuário e a gestão.

A existência desse muro, contudo, não implica uma impossibilidade. $O$ muro talvez represente melhor uma condição de acesso, cuja transposição, entretanto, deixa suas marcas naquele que o transpõe. $\mathrm{Na}$ figura, o Controle Social, em sua acepção mais comum, se refere ao lugar de gestor que os cidadãos representantes de um coletivo podem assumir em colaboração com a gestão formal das instituiçôes do campo da saúde. O usuário, por sua vez, ao exercer seu papel de cidadão, pode ser convidado ou se sentir convocado a realizar essa função gestora dos serviços do qual é beneficiário, mas o faz com dificuldades de várias ordens. Depara-se com resistências diversas, desde as declaradas, no contato com o gestor sustentado em seu discurso técnico do qual o usuário não faz parte, até as subjetivas, constrangedoras ao próprio usuário que, embora se sinta no direito de participar da gestão do serviço que o atende, ressente-se ao perceber que sua lógica não parece ter o mesmo valor que a do técnico. É da mesma ordem o exemplo da situação de constrangimento que o usuário comum revela sentir quando não compartilha o mesmo linguajar usado pelo técnico nas reuniōes deliberativas, podendo não compreender o que é argumentado ou julgar desqualificada sua intervenção por não saber se expressar daquela maneira.

Por outro lado, na medida em que existe um local legitimado de participação, como as Conferências e Conselhos, municipais ou locais, de Saúde, parece que existe a possibilidade da transposição do muro representado na figura 1. Resta refletir se o usuário, atravessado pelos efeitos do muro da ciência, não viria a constituir um tipo de discurso com o ranço do cientificismo que, paradoxalmente, costuma excluí-lo. Avançando na mesma linha de raciocínio: o discurso que hora chamamos do usuário não correria o risco de produzir-se como uma corruptela do discurso da gestão ao ocupar o lugar de mestria? Será que não encontramos exemplos disso na prática?

As últimas reflexões colocam uma nova questão, importantíssima dentro da proposta de uma teoria dos discursos que organizam o campo da saúde. Resgatando a impressão segundo a qual não se pode prescindir de um sujeito no âmbito do que se refere ao discurso do usuário, pergunta-se: visto que o suposto discurso do usuário, na condição de sua viabilidade no processo de cuidado 
integral à saúde - o que inclui a gestão e o ensino, além da atenção - correr o risco de se organizar apenas como uma corruptela do discurso da gestão ao transpor o muro da ciência, em que medida ou em que situaçôes seria rigoroso considerá-lo como um discurso singular na estrutura?

Até que se desenvolvam reflexões e pesquisas com o dispositivo e o conceito dos discursos do campo da saúde propostos neste ensaio, parece prudente manter a ideia da existência de um discurso do usuário e derivar disso as decorrências, a exemplo dos demais discursos. No momento apenas levantar-se-á a hipótese de, talvez, ser mais rico para a pesquisa e adequado à realidade, considerar o elemento chamado de usuário como o sujeito (ver nota 6) da estrutura formada pelos demais discursos, ou seja, o que excede e provoca a subversão em determinado discurso dominante.

Uma colocação final: a problematização da formação e do desenvolvimento do profissional da saúde, estabelecida no jogo estrutural entre os discursos constituídos pela interação de cada elemento da lógica proporcionada pelo quadrilátero da formação, de Ceccim e Feuerwerker (2004), parece indicar que o ensino (aqui, como termo ocupante de lugares no dispositivo e não como discurso) tenha algum potencial de papel transferencial para essa mudança de discurso almejada. Porém, pode o elemento de ensino escutar o desejo produzido por um discurso na Saúde que se organizaria a partir do usuário elevado à posição de mestre? Por outro lado, observa-se que o Discurso do Ensino, através de seus dispositivos (Universidade, cursos técnicos e pós-graduação), não se sustenta pela atenção no lugar de verdade (como só é proposto pelo discurso do usuário). Sendo assim, pergunta-se: que pesquisa, que objeto ainda desconsiderado pelo interesse científico, pode proporcionar um caminho para a descoberta da condição de possibilidade de o ensino ocupar esse lugar transferencial que permita a mudança de discurso subentendida no artigo do Quadrilátero, se interpretado como viemos propondo até o momento? E, finalmente: existiriam outros meios para que isso ocorra, além do que pode ser proporcionado, supostamente, pelo ensino?

Restam muitas questóes e a expectativa que as propostas deste ensaio ${ }^{7}$ reverberem em outros pesquisadores de interesses comuns, para que o dispositivo construído e apresentado através deste ensaio seja colocado à prova e, fortuitamente, auxilie na elaboração de respostas e futuras perguntas. 


\section{Referências}

AYRES, J. R. C. M. Cuidado: tecnologia ou sabedoria prática? Interface: comunicação, saúde e educação, Botucatu, v. 6, n. fevereiro, p. 117-120, 2000.

. Sujeito, intersubjetividade e práticas de saúde. Ciência e saúde coletiva, v. 6, n. 1, p. 63-72, 2001.

CECÍLIO, L.C.O. Modelos tecnoassistencias em saúde: da pirâmide ao círculo, uma possibilidade a ser explorada. Cadernos de saúde pública, São Paulo, v. 13, n. 3, p. 469-478, jul./set.1997.

CECCIM, R. B.; FEUERWERKER, L. C. M. O quadrilátero da formação para a área da saúde: ensino, gestão, atenção e controle social. Physis, Rio de Janeiro, v. 14, n. 1, p. 41- 65, 2004.

CECCIM, R.B. Educação permanente em saúde: desafio ambicioso e necessário. Interface: comunicação, saúde, educação, v. 9, n. 16, p. 161-77, 2005.

FREUD, Sigmund. (1915) Observaçōes sobre o amor transferencial. In: Obras completas Edição Standard Brasileira, v. XII - Rio de Janeiro: Imago, 1969.

HECKERT, Ana Lucia C. Escuta como cuidado: o que se passa nos processos de formação e de escuta? In: PINHEIRO, R.; MATTOS, R. A. de. (Org.). Razôes públicas para a integralidade em saúde: o cuidado como valor. 1 ed. Rio de Janeiro: Abrasco. p. 199-212, 2007.

LACAN, J. A ética da psicanálise. O Seminário: livro 7. Rio de Janeiro: Jorge Zahar, 1988. . O avesso da psicanálise. Seminário: livro 17. Rio de Janeiro: Jorge Zahar, 1992. . Mais, ainda. O Seminário: livro 20. Rio de Janeiro: Jorge Zahar, 1985. Televisão. Rio de Janeiro: J. Zahar, 1993.

RINALDI, D. O acolhimento, a escuta e o cuidado: algumas notas sobre o tratamento da loucura. Em Pauta: Revista da Faculdade de Serviço Social da UERJ, Rio de Janeiro, n. 16, p. 7-18, 2000.

\section{Notas}

${ }^{1}$ A ser verificada em seus pressupostos, pois cabe lembrar que no nascimento da clínica esta se referia à visão ampla do processo de adoecimento.

${ }^{2}$ Talvez o único recorte possível para ilustrar um efeito do discurso do técnico seja: “... se considera dispensado da escuta à pessoa”. Entretanto, embora a frase se refira ao trabalhador em saúde, este só aparece no discurso por seu sintoma: a desobrigação de escutar o relato do sofrimento subjetivo do paciente - afinal, talvez julgue antecipadamente saber o que o paciente necessita, apoiado no que sua ciência lhe diz. Aquele a quem é negado um lugar no discurso acaba por produzir uma insurgência no mesmo, um sintoma. Para outra reflexão, o seguinte aforismo: três elementos sustentam uma estrutura, mas o elemento excluído faz sintoma; pelo menos até que seja escutado, como nos advertiria o saber psicanalítico. Ao nos reportarmos ao artigo, quem não é escutado, segundo os autores? 
${ }^{3}$ Portanto, sem palavras, pois o que vale não é o que é dito pelo político. O AI-5 é um exemplo de ato que institui o discurso do mestre em sua forma ditatorial.

${ }^{4}$ Os efeitos dos discursos não se resumem a espaços fixos. O discurso da educação pode mostrar seus efeitos até mesmo em uma discussão informal na qual um dos interlocutores assume todo o saber sobre o assunto e deseja ensinar o outro.

${ }^{5}$ Por instituição de saúde, o leitor deve entender tudo o que é produzido socialmente nesse campo, desde as leis que regulamentam a saúde no país, passando pelo que ocorre nos consultórios, unidades ou hospitais, em termos de ações, práticas ou dispositivos de formação em saúde.

${ }^{6}$ Sujeito deve ser entendido neste ensaio como uma insurgência na estrutura que organiza determinado laço social e não confundido com o indivíduo jurídico de carne e osso.

${ }^{7}$ Este artigo é fruto de discussōes realizadas diretamente com Ricardo Ceccim, um dos autores do artigo que o originou, numa disciplina do doutorado da FACED em que fui seu aluno. 
The construction of a device for studying the discourses that organize the health area: an essay on the discursive effects and the health professional training Starting from the central ideas of the paper "A fourway approach to training in the health field: teaching, management, care, and social control", by Ceccim and Feuerwerker, published in 2004 in this journal, the author brings a contribution to this subject by proposing a theoretical essay in which each element of the four-way approach will be thought as specific discourse. To do that, Lacan's four discourses theory is brought in to build each discourse and to do the first analyses of the effects on training in health. After an elementary introduction about that theory, the author tries to articulate the fourway approach elements and built with his reader each one of the discourses, namely Teaching, Management, Care, and Social Control. The latter has been worked with more detail, according to the arguments of the original paper which gives it importance, and is now renamed as the User's Discourse to highlight the subjective element on that one. Finally, future researches paths are presented from several interrogations allowed by the construction and first analysis about the study on discourses effects. This work intends to collaborate in the same research line of the paper that inspired it by putting on questions to clarify the subject of Social Control discourse's possible conditions to interfere and produce the acts on health field as well as an element of the professional health training.

Key words: training on health; social control; four discourses; Lacan; health worker's education. 